\title{
QUEEN'S
UNIVERSITY
BELFAST
}

\section{When risks meet: The dance of experience, professional expertise and science in border security technology development}

Degenhardt, T., \& Bourne, M. (2018). When risks meet: The dance of experience, professional expertise and science in border security technology development. Criminology and Criminal Justice, 20(2), 207-225. https://doi.org/10.1177/1748895818811896

Published in:

Criminology and Criminal Justice

Document Version:

Peer reviewed version

Queen's University Belfast - Research Portal:

Link to publication record in Queen's University Belfast Research Portal

Publisher rights

( 2018 The Authors. This work is made available online in accordance with the publisher's policies. Please refer to any applicable terms of use of the publisher.

\section{General rights}

Copyright for the publications made accessible via the Queen's University Belfast Research Portal is retained by the author(s) and / or other copyright owners and it is a condition of accessing these publications that users recognise and abide by the legal requirements associated with these rights.

Take down policy

The Research Portal is Queen's institutional repository that provides access to Queen's research output. Every effort has been made to ensure that content in the Research Portal does not infringe any person's rights, or applicable UK laws. If you discover content in the Research Portal that you believe breaches copyright or violates any law, please contact openaccess@qub.ac.uk. 


\section{WHEN RISKS MEET: THE DANCE OF EXPERIENCE, PROFESSIONAL EXPERTISE AND SCIENCE IN BORDER SECURITY TECHNOLOGY DEVELOPMENT*}

TERESA DEGENHARDT, Lecturer in Criminology

MIKE BOURNE, Reader in International Security Studies

\section{Abstract}

As policing and threats become increasingly transnational and plural, practices of managing risk increasingly use technologies that promise certainty. Drawing on a study of the creation of a new border detection device, and ideas from Science and Technology Studies, we argue that devices deployed as objective tools for risk assessment and management in the policing of borders, and the laboratories that develop them, are not simply linear applications of scientific knowledge to control risk but rather are crucial sites in which multiple and contending conceptions and practices of risk converge. Following the interactions of scientists, border guards, policing agents and the EU shows how an official discourse of risk, a scientific conception, and experiential working knowledge of risk all 'danced' together in the development of a portable detection device. In the process experiential/contextual and professional knowledge of risk were often privileged over rationalistic and statistically based risk assessment.

Key Words: risk, security, technology, border, policing, CBRNE

\footnotetext{
* The authors are grateful to Robert Miller, Sarah Moore and the anonymous reviewers for comments on a previous draft, and to all those that kindly agreed to be interviewed and collaborated with the research process.
} 


\section{Introduction}

One of the cornerstones of the EU is the free movement of people and goods, but since $9 / 11$, security and crime control have become a central concern. With increased concern about transnational terrorism, our inability to predict risk has become apparent, causing us to privilege the prediction of catastrophes in the governmentality of the future (Aradau and van Munster, 2009). According to Amoore "the imagination of "low probability, high consequence" events has become an overwhelming feature' in how we understand risk (2013: 1; Beck 1992, 2013; Douglas, 1994; Giddens, 1991). Borders now play a crucial role in the regulation of risk (Aas, 2005; Bowling, 2013; Pickering and Weber, 2006; 2013; Wonders, 2007). The employment of technology, particularly algorithmic technologies, information systems, and biometrics, is now hailed as a 'magic bullet', 'an absolute security provider' (Marx, 2005; Ceyhan, 2008: 102), an 'ultimate solution' to 'the unknown and risk generated by globalization and reinforced by September 11' (Ceyhan, 2008: 103). In short, then, technology is supposed to make known and authorise decisions in the face of a radical 'non-knowing' (Walklate and Mythen, 2016: 408). Technology increases the capacity to surveil and control, combining crime control and containment with the possibility of pre-emption (Marx, 2005; Wilson, 2006; Bowling, Marks and Murphy, 2008). In doing so, as Katja Franko 
Aas claims, 'contemporary technological paraphernalia...not only enables fortification of the border, it also reshapes the border according to its own logic.' (2005: 208).

This article explores how risk and security are engaged by those that create security technologies. It is based on a social science study of an EU-funded technology research project in which scientists and laboratories across Europe engaged with enduser border guards to develop a handheld device to detect CBRNE (chemical, biological, radiological, nuclear, and explosive $)^{\dagger}$ smuggling at EU borders. The article contributes to the growing engagement with borders and risk across the fields of criminology and security studies (Aradau and Van Munster, 2009; Bigo, 2016; Mythen and Walklate, 2016; Crawford and Hutchinson, 2016). It expands knowledge of the governance of security (Wood and Shearing, 2007) by highlighting the role played by research groups and laboratories in shaping emerging modalities of transnational policing in the context of international terrorism. In doing so we show how diverse actors' engagement with different forms of risk, ways of knowing risk, and security narratives combined and redirected technology from catastrophic risks of CBRNE terrorism towards wider materials and modes of policing at borders by detecting cocaine, tobacco, explosives and radiation.

\footnotetext{
$\dagger$ The literature, policy and practice in this area sometimes refer to CBRN (chemical, biological, radiological and nuclear) materials and terrorism, and at other times to CBRNE (adding conventional explosives). We use both terms, following the sources cited.
} 
We draw on concepts from science and technology studies (STS) to engage the social and political dimensions of the processes of technology development within the laboratory as a crucial component in the determination of seemingly neutral and objective rationalities deployed by the technology. We argue that a device is more than just a technological tool and should be seen as an important component in the process of transnational policing (Bowling and Sheptycki, 2015) and in the deployment of specific rationalities in the governance of security. We ask, given the heterogeneous nature of the scientific process, how are supposedly apolitical, technical, 'objective' facts of risk formulated to create the rationale for a device alleviating risk? Engaging STS allows us to open the 'black box' of technology to scrutiny by exploring how the device is built. However STS rarely engages security technologies. In criminology, to our knowledge, no one has explored how specific logics and rationalities enter technological development with a consequent impact on security practices, in spite of some authors' encouragement to do so (Valverde, 2011; Zedner, 2009). In criminology, technology has mostly been analysed in its later use - such as in practices of surveillance and border control and their social sorting effects and discriminatory practices enacted against those considered risky (Lyon, 2003; Wilson, 2006; Aas, 2005). In this sense, scholars have rightly pointed to the need for procedural and ethical rules to regulate technology, warning of possible violations of human rights (Bowling, Marks and Murphy, 2008). Here, we argue it is also important to open up technology and 
laboratories to political scrutiny given the important roles they increasingly perform in the production of security at borders and in policing. In doing so, we uncover the specific narratives of risk and uncertainties engrained in the process and how they are framed, combined, and worked through.

Overall, we argue that technologies and the laboratories and collaborations that produce them are crucial sites in which multiple and contending conceptions and practices of risk converge. We show how the certainty provided by a technological device is contingent on a combination of uncertainties, of heterogeneous interactions of humans and matter, and the multiple forms of risk and risk knowledge scientists engage, escape or supplement. We suggest that these sorts of engagement, to cite STS scholar Andrew Pickering $(1995,2017)$, are a 'dance of agencies'.

The article first situates our argument in the literature on policing, risk and security and the use of technology, and formulates our notion of the 'dance of risks'. We then outline our methods, before turning to the analysis of our findings on how diverse risks and risk management practices are combined in practice. We argue technology development is not a neutral procedure: it is a complex process involving many sorts of exchanges between scientists, policing agents and border guards, and the EU, with a range of devices, dangerous materials, and forms of scientific knowledge. We show how an official discourse of risk, a working knowledge of risk, and a scientific conception all "danced" together as they combined to create a portable 
detection device. In the process experiential/contextual and professional knowledge of risk were often privileged over rationalistic and statistically based risk assessment. We draw this out through explorations of how the decisions about what to detect emerged through particular combinations of catastrophic and mundane threats and logics; how the laboratories became attuned to the ways risks are engaged at the border; and the ways scientists engaged their own everyday uncertainties through technical savoir, gut feeling and imagination. We conclude by highlighting the transversal significance of experiential and professional knowledge across these dimensions.

\section{Policing risk and security at the EU border: staging sovereignty and control through technology}

In this article, we argue that security technologies are not merely neutral devices produced in isolated laboratories and then deployed at border sites (Bourne et-al, 2015), but important components that shape emerging modalities of transnational policing of borders. Such technologies are inherently political assemblages even before their deployment, and following their production allows us to trace multiple risks and uncertainties as they combine and emerge in the interactions of multiple actors, matter, and policing rationalities.

It is now common to look at policing as broader than what the police do (Haggerty and Ericson, 2000; Wood and Shearing, 2007; Bowling and Sheptycki, 2015; 
Crawford and Hutchinson, 2016) and to understand issues of crime as related to other forms of external threats under the wider umbrella of security. We see technologies as more than simple policing tools, we view the process of technology development as an important process in the development of policing logics emergent in the interactions of scientists, end-user border guards, bordering practices, and material agencies. As such we see both technology and border policing as assemblages in which multiple forms of risk knowledge and practice are combined.

Assemblages are heterogeneous, self-organising arrangements of different elements, comprising people and things, the unity of which - is only ever provisional, constituted by their contingent relations based on connections of these heterogeneous elements and that cannot be reduced to its components (Schuilenburg, 2015), 'The assemblage's only unity is that of co-functioning: It is a symbiosis, a "sympathy"” (Deleuze and Parnet 2007: 69). What is important, then, is that assemblages do not diminish differences so much as draw them together as they work together. Border policing, risk management, the project we studied, and the device it produced, are all assemblages in this sense.

In their seminal work, Ericson and Haggerty (1997) highlight the need to look at policing as 'risk communication' and to consider how other institutions identify and manage risk. The logic engrained in specific systems of communication shape the ensuing modalities of policing, altering established structures of command and control 
and both circumscribing and dispersing discretion (Ericson and Haggerty, 1997). In this framework, we explore what kind of rationalities and practices of risk entered the development of a technological device to detect CBRNE. We show how risk logics were communicated and combined, thus highlighting some of the structures of control and forms of discretion engrained and dispersed within the seemingly neutral technological tool.

Technology development is a complex process. The detection device we discuss here is aimed at the surveillance and detection of dangerous materials, including CBRNE. It manifests the 'desire to control' substances rather than individuals (Guzik, 2016), relying on machines able to transform material traces into information and communicate the danger lurking in some substances to manage and 'make visible the invisible' threats (Haggerty and Ericson, 2000). In following the creation of such a device, we wished to explore what specific forms and understanding of risks were engrained. We found that various forms of knowledge, practices, resources and mentalities from different 'nodes' (Wood and Shearing, 2007) are integrated and assembled (Haggerty and Ericson, 2000). The project was intended to develop and integrate technologies that are usually separate (sensors for different types of substances) into a portable unit to engage the mobility of threats. In doing so multiple laboratories with different scientific specialisms, national cultures and types (academic and commercial) came together with end-users. In the laboratories, the detection device 
ended up incorporating and assembling diverse risk narratives enabling the detection of different security threats at the border. Rather than using notions of risk as probabilities, different narratives of risk were present, thus confirming previous research on risk.

Risk determinations and narratives have changed the way the criminal justice system operates and is managed, eliding the role of professionals and experts (Feeley and Simon, 1992; Castel, 1991; Ericson and Haggerty 1997; Garland, 2001). However, recent empirical studies have demonstrated how different logics co-exist and merge with statistical and rationalistic understandings of risk as they are operationalized within the criminal justice system (Werth, 2017; Mythen and Walklate, 2011; Kemshall 2010; Kemshall and Maguire, 2001; O’Malley 1992; 1999; 2004; Hannah-Moffat, 1999; 2005; 2010; Hutchinson, 2006). Actuarial knowledge combines with, rather than eradicates, discretionary decision making, with 'experience', 'gut feeling', 'experts and practitioners' knowledge' becoming important components in the determination of uncertainty, evidencing the presence of affective, experiential and moral judgements (Werth, 2017; Hannah-Moffat et-al, 2010). Experiential knowledge and 'knowing otherwise', rather than being seen as 'wrong knowledge', are used in extremely complex situations and in the context of great uncertainty, with multiple actors contributing to the final determination of risk (Baillegeau and Duyvendak, 2016; Walklate and Mythen, 2011). Our research confirms these findings in different 
empirical settings, highlighting the role that experiential and practical knowledge has in the process of technology development. .

We trace this multiplicity of forms of risk in the development of the device. We argue that technologies are not simple linear applications of scientific knowledge to policing problems. As STS literature shows, laboratories both produce reality and are themselves a product of a contingent and specific set of social relations (Latour and Woolgar, 1979). Laboratories incorporate 'exchanges between specialists and the world that surround them' (Callon et al, 2001: 47). We sought to follow these exchanges to reveal that the 'scientific knowledge' produced through the device is not just one form of risk knowledge among others, but is itself prefigured and constituted through multiple ways of knowing risk. In this case, the device is the contingent outcome of interactions between those with actuarial and experiential knowledge, between gut feeling and empiricism, between scientists and engineers, border officials, government institutions and others. Indeed, the ways different modes of knowing risk are connected and translated into each other were central to drawing together the different professional cultures of scientists and border guards. In particular, situated knowledges of everyday experience emerged as central: sometimes overriding the value of catastrophic risk, and probabilistic determinations, sometimes 'de-risking' the uncertainties of technology development, sometimes allowing scientists to translate the advice of end-users into their own practices. 
In exploring how different narratives of risk are assembled in the technical and supposedly objective tool, we borrow two metaphors from Andrew Pickering's work in STS. For Pickering, technology development draws together multiple forms of agency: both human and non-human. The first metaphor is 'tuning' (as one might tune a radio, a car engine, or a piano). This resonates with the goals of the handheld border device. It was intended to detect the presence of risky substances by finding traces of radiation, cocaine, tobacco etc. The instrument being created must 'tune in' to the identifiable signatures, frequencies, etc. of the risky material. Pickering's metaphor extends to include how scientists orient themselves to the action, the agency, of their target substance. In this process, uncertainty is high: 'No one knows in advance the shape of future machines and what they will do' (Pickering, 1995: 14). An important component of technology development is the responses that different materials provide to the actions of scientists. How, then, do scientists 'tune in' to the agency of matter and enrol it into the actions of border guards in policing borders?

In the second metaphor, Pickering says tuning occurs in all 'goal-oriented processes' of scientific practice as a 'dance of agency'. In this dance metaphor, Pickering introduces a temporal dimension to the interaction of scientist and material, whereby, in a 'dialectic of resistance and accommodation' (Pickering, 1995: 22), engineers produce new tools. Here humans and non-humans act together, in a process characterised by periods of action and passivity taken in turn: 
As active intentional beings, scientists tentatively construct some new machine. They then adopt a passive role, monitoring the performance of the machine to see whatever capture of material agency it might effect. Symmetrically, this period of human passivity is the period in which material agency actively manifests itself. Does the machine perform as intended? Has the intended capture of agency been effected? Typically the answer is no, in which case the response is another reversal of roles: human agency is once more active in a revision of modelling vectors, followed by another bout of human passivity and material performance, and so on. (Pickering, 1995:21-22)

In this way, the scientist and the machine interact, 'dancing' together, each leading in turn, each revising the other, by which they become attuned.

This insight sheds light on how risk was engaged within the context of the laboratory creating the final prototype of the handheld border device. If part of the operation of risk lies in the production and circulation of seemingly concrete scientific facts (the calculation of a probability, the detection of something dangerous) then by combining the exchanges between the laboratory and the wider world and their multiple dances, we can begin to explore how ostensibly stable 'facts' become established. The production of the device we observed could be described as a process of becoming objective: a risk calculus in the form of a handheld device that appeared to 
satisfy the demands of a degree of certainty on tracing CBRNE and cocaine or tobacco. Such products of science and engineering are characterised by Latour (1987) as 'immutable mobiles', (machines, representations, readings, data, etc.) that can travel freely and be (relatively) unchanged by that movement. They are the assumed universals of scientific knowledge or technological materiality, but in fact are always the product of multiple 'dances' such as those between scientists, policing actors, and matter and machines in the handheld device which combined different risk logics and practices to produce a stable representation of risk to inform border decisions and thus to stage sovereignty and certainty at the EU border.

\section{Methods: unpacking risks in border security technology development}

Our research is based on a larger social science study of an EU-funded FP7 project. The FP7 project involved nine partners, a mixture of academics, including biologists, physicists, chemical and software and hardware systems engineers, as well as SMEs, and border guards (police and customs organisations). Scientists came from five EU countries: Ireland, Germany, Portugal, Estonia, and the UK. Our data were collected over 20 months (March 2013-October 2014) by an interdisciplinary group of five social scientists drawn from criminology, sociology, and international relations scholars, as well as two co-investigators from engineering disciplines. Intensive data collection for 
the observation study began at month six of the FP7 research project and ended just after the demonstration of the first working prototype to the funders in month $24 .^{\ddagger}$

Our collective multi-sited and multi-disciplinary study (Marcus, 1995; Erickson and Stull, 1998; Clerke and Hopwood, 2014; Falzon, 2016), included 50 in-depth interviews with all major participants in the project, as well as government officials and other technology companies; observation of all major project meetings, interactions with European funders, trade fairs such as Counter Terrorism Expo, and the daily work of scientists and engineers in their laboratories across Europe. We also observed and interviewed some customs and border guards at work at borders. We organised discussions in workshops with wider stakeholders from government and industry to expand and validate our findings.

Quotations from interviews were taken from audio recordings and transcriptions; those from meetings and observations were taken with more traditional paper and pencil during or immediately after the event by scholars on the team; they were shared and in most cases discussed collectively (Erickson and Stull, 1998; Clerke and Hopwood,

\footnotetext{
Although we followed only this project in depth, potentially limiting the generalisability of our findings, we sought to validate our findings through wider discussions and interviews with industry, government officials responsible for security technology development, and other projects funded under the same call. Notably, many other projects had more limited end-user engagement (observation and private conversations). Approximately $70 \%$ of FP7 security technology projects incorporate end-user roles, but they are often confined to advisory panels (CSES, 2011). In our engagements with end-users, industry, and others, we found that gaining access to end-users is challenging for smaller companies and research organisations. Our observations of the project lasted until the first prototype. However, through interviews and some prior engagement with the project, we were able to gain a sense of the project at the proposal stage; we continued our engagement in some key events after the end of our observations.
} 
2014). To maintain anonymity, our references omit information on the professional tasks of our informants, providing only the date of data collection. We gained access to the above-mentioned scientific project through previous professional connections with lead scientists. In the process, we were surprised by the researchers' openness at sharing what they were doing. However, we were required not to divulge the data we were collecting until the end of the project.

Deciding what to detect: the assemblage of the catastrophic, the mundane, crime and competitive logics

Since 2001, combating CBRNE smuggling and terrorism has been integral to EU security practices. Strong emphasis is placed on portable detection technologies for border control, alongside and reinforcing risk profiling and intelligence (European Commission, 2007; 2014). ${ }^{\S}$ In 2010 the EU called for the production of handheld technological devices able to detect various possible threats:

[The] integration of different technologies for the detection of illegal substances and hidden persons, border control [is] closely linked to custom control of goods (this category comprises inter alia weapons, drugs, CBRNE, legal goods subject

\footnotetext{
$\S$ CBRNE detection has a strong economic dimension, with technologies linked to the development of 'a European Market for security products and systems' (Case Study of CBRN, 2011). The fear of CBRNE terrorism is driving growth in the global market for detection equipment, predicted to increase from US\$2.2billion in 2015 to US\$9.8billion in 2022 (RNR Market Research, 2016). This would exceed the global market for policing equipment (US\$7.08billion in 2016) (Visiongain, 2016).
} 
to duty, good subject to import or export restriction and those that fail to meet health and safety standards). (European Commission, 2010: 24)

Catastrophic terrorism, public health, duty revenues and organised criminality were loosely linked in the initial call, demonstrating how different fields of security overlap (Crawford and Hutchinson, 2016). Most of the projects funded under this call, however, prioritised CBRNE.

While the European Commission emphasises research capacity, it always seeks to meet the challenges and needs of public service (observation, 22/5/2014). ${ }^{* *}$ Thus, the EU requires research teams to involve end users (in this case, border guards and policing agents) from the beginning to ensure effectiveness (Observation 22/5/2014; Interview A 14/3/2015). In the project we studied, end users were integrated from the start of the project and - to varying degrees - participated in technical meetings, provided testing and demonstration opportunities, took scientists to borders to see daily practices, and provided input on detection thresholds, user interfaces and so forth.

The specific end-users involved in the project we observed, and others called in to comment on it, played a prominent role in determining the utility of the technological device. As it happened, end-users were generally more concerned with the detection of illegal and more mundane substances in their daily and local contexts, than with the

\footnotetext{
** EU representatives consistently emphasized the importance of having a final working device, so the funding could be seen as successful.
} 
detection of highly dangerous materials specified by the EU (linked to terrorism or rogue states).$^{\dagger \dagger}$ Their understanding of this aspect of risk was strongly linked to their fundamentally practical and local experience in their specific professions/roles and geopolitical locations. Indeed, in general, border guards were perplexed by the prominence of CBRNE in EU concerns. While acknowledging that CBRNE should be monitored, they argued that such issues were uncommon and thus the end-users felt that the EU call was not in tune with their operational needs. They variously commented: 'Tobacco and cigarettes would be extremely successful [and] trade in illicit medicines is huge'; 'I do not have explosive letters, I do not have it, why be concerned about it?'(Observation, 9/5/2013); 'The greater chance of the device being used is in cocaine, so it would be more successful... and you can have results every day...' (Interview A 16/7/2014). In other words, the end-users contested the search for the 'exceptional and the catastrophic' and went back to their local knowledge of what was most likely to impact them. In some contexts, it was cocaine, and in others it was tobacco and similar items. When the scientists 'tuned in' to them (inviting them to the 'dance'), these specific local priorities were incorporated into the device as if they were the main threats, even if they

\footnotetext{
${ }^{\dagger}$ In this project many end-users were limited their participation to providing operating scenarios. This meant that those that were more closely involved had more influence, as did some special-end users and border guards brought to the table by the EU to ensure maximum return on its new device. Indeed, the EU organised a number of events in which various projects were presented to different end-users and guards from all over Europe. At a meeting we attended, border guards came from countries at the edge of the EU: Poland, Slovenia, or even the UK.
} 
might not apply in other contexts and even if they did not perfectly match the original EU concerns.

The scientists were less concerned about the substances to detect. They turned to the end-users because they saw their particular practice-based knowledge as more likely to guarantee the success (i.e. utility/profitability) of their research (Interview A, 28/10/2013). One asked, 'What's the point if you're detecting things that no one really cares about?' As he said, the end-users put 'expert knowledge on the table right away" (ibidem). Even though the EU had made the call for research, and funded the project, the EU was not perceived as the expert in determining the devices needed at the border. This raises questions about the distinction between professional/expert knowledge and ways of 'knowing otherwise' (Walklate and Mythen, 2011; Baillergeau and Duyvendak, 2016). Professional risk assessment tools often leave out forms of knowledge -the "knowing otherwise' - based on the intuition and everyday experience of some less powerful subjects (Walklate and Mythen, 2011). In our study, instead, it appears that even if the EU policy seemed to be privileging low probability and high consequences risks, it also allowed for some professional end users to incorporate their everyday and contextual understanding of what constituted risk- their 'knowing otherwise'- as a way of guaranteeing the greatest certainty and security at the border. In this case, therefore, expert knowledge was the knowledge coming from specific everyday experience and understanding of context. 
Overall, the determination of what risky substances were worthy of detection at borders was not derived from formal threat assessments but from the interaction of various subjects' knowledge and understanding of everyday 'risk' at the border. Scientists negotiated within the parameters of the funding call but attributed greater relevance to those able to speak in everyday practical terms about their experience of risky substances at borders.

This was a heterogeneous collection of practitioners, drawn from different countries and types of institutions. Although they could all be broadly categorized as policing agents, they had quite different focuses and understood the technology under construction as facilitating different activities. Some saw it as facilitating routine border checks; others conceived it as a tool to facilitate investigative work in a larger area. When their views of risk were taken seriously, the device incorporated heterogeneous policing aims. Some end users privileged the search for cocaine and others for tobaccoas they believed these to be more interesting from their knowledge of border policing, while scientists kept some interest in the detection of radiation. Ultimately, the device showed neither a predominant form of risk, nor a rationalised hierarchy of risks. Rather, the aims of the technology shifted to incorporate local and national risks, criminal and taxation enforcement priorities. By the end of the project, the multiple sensors on the device could detect cocaine, tobacco, explosives and radiation and could be tuned to other substances in future. The mundane and the catastrophic were assembled together 
within the technology to meet the needs of quite different policing agents and of different scientific possibilities.

\section{Risk inscribed in the technology: attuning worlds in the lab}

While the project articulated 'risk' in terms of substances of concern, there was also a common perception - shared by scientists from all fields and acknowledged by end-users - that technology itself is 'risky'. There was a general understanding that the biggest challenge of the handheld device was 'getting it to work in the field'. Engaging this risk animated much of the scientific collaboration - as scientists frequently invoked wider conversations with border guards who spoke of 'storerooms full of equipment' (multiple observations and interviews) that worked in the laboratory but not in the field. Addressing this particular 'risk' required attuning scientific and engineering practice to the messy material world of bordering. Border guards said that in the absence of evidence showing its utility, the technology might not even be considered, as generally speaking, manufacturers' claims and stated capabilities 'are not considered reliable' (Interview A, 18/11/2013). 'Having it tested by a user group' is important (Observation 3/3/2014). Their worries included that it might not be successful at a certain distance or speed, or it could result in false negatives (making the device useless) or false positives (making people lose confidence in results) (Observation, 18/11/2013). The literature points to the general reluctance of policing agents to adopt new technological devices 
(Manning, 2008); there is greater trust in experience, especially direct personal experience, than in the market. Indeed, those we talked to said many existing devices were not being used as they were too time consuming and yielded too few results for the time involved (Observation, 18/11/13). They tended to use them only if suspicion was multiple and well-founded. Thus the risk of failure was translated into the risk that the device was not attuned to fitting in with the multiple ways border guards tend to sense risk at borders. Would it be fast enough to fit with the routines of guards and the flow of traffic? Would the battery last long enough? Etc.

In bordering practice, the human ability to suspect a package or a person seems to be trusted more than technology (Observation 18/11/2013; multiple private conversations; see also Bigo, 2014). When asked about their procedure to determine risk, border guards at ports, in postal depots, or at airport arrivals of both cargo and people, strongly argued that 'everything that sticks out' (Observation and interviews $18 / 11 / 2013$ ) is risky. 'People who are nervous' or 'big companies but weird ways of delivery' may trigger concern (ibidem). The method of delivery and collection is seen as something to pay attention to, especially 'what is not collected in person'. Risky parcels are 'sensed' though common sense and experiential knowledge of what is unusual: these include parcels not directly related to a phone line or an address, not paid for, not having gone through the security checks etc. (Observations and private conversations $18 / 11 / 2013$ ). Risk is also more prosaically identified with specific ports 
or countries of origin: Rotterdam, Dublin, Latin America and Spain are seen as risky (ibidem). This again suggests the use of situated knowledge and of 'knowing otherwise' in the detection of risk.

To the border guards, technology simply cannot identify some crucial differences that can be 'sensed'. Risk is not a single dimension that can be spotted by a handheld device: it is omnipresent, loose, and emergent from a combination of target substances, detection devices, routines, personal experience, and, importantly, the conditions of a particular operating context. Here, ways of knowing risk are entangled with material conditions that helped translate experiences into engineering tasks. For example, by the middle of the project, it was clear that the device had to operate at temperatures between -40 and +50 Celsius to accommodate countries at the extreme latitudes of Europe. This requirement then anchored numerous other practical questions that border guards raised in the context of group meetings when the development in the laboratories and future moves were presented to them. Could gloves be used with the user-interface? Was the display big enough? Would the tool really be portable? Was the detection time sufficient for each location of control? A postal sorting office presents a different challenge from a busy airport, for example, and a small border space is qualitatively different from a large border space.

These real-life scenarios and their risks provided by the end users helped the scientists make design decisions. They 'tuned' the technology to the various imagined 
environmental and contextual conditions at the border, as a way of scaling down the risks (linked to the development and deployment) inherent to the production of technology. This suggests that technology is not inherently universal; it has to be made so by making it work in all imagined fields. In a context of great uncertainty (not just uncertainty and risk at the border, but risk within the lab), the scientists turned to the experiences of policing agents to refine the parameters of this. As other researchers note, the calculative probabilistic narrative of risk is only followed when it agrees with practitioners' understanding in cases of great uncertainties (Baillergeau and Duyvendak, 2016; Mythen and Walklate, 2011). In this case, the experts were valuing risks on the basis of their 'knowing otherwise' the way in which policing happens at the border, in specific contexts and within specific circumstances.

Although risk is often conceived as a particular means of anticipating and acting upon the future through scientific means, we found that the practice of developing those scientific means included a combination of less probabilistic forms of anticipation and action, of past experience and personal knowledge. The handheld device is the result of these varied experiential considerations. The device must be able to work in particular contexts, including the interaction between the policing agent and the material context of the work. Developing the technology meant accepting, not eliminating, the experiential - even instinctive - practical sense of the border guards that was perceived to be the professional knowledge needed to make the device work. 


\section{Dancing with risk in the lab: technical savoir, gut feelings and scenario imagination.}

Although the scientists working on the project referred to risk and 'de-risking,' they admitted that their emphasis on risk came from pressure from the EU. It was mostly a way to 'talk back' in the language of the call, part of the strategy to please the Commission. One scientist said, 'the risk analysis part was crucial to the negotiation stage, it was something highlighted by the reviewer' (Interview 29/10/2013; European Commission, 2010). Another commented: 'the idea of risk analysis was something that was relatively foreign, believe it or not, to the scientists in the proposal in the early days' (Interview 29/10/2013). Some had experience of risk analysis from their background in industry: 'The risk input was mostly coming from one scientist's experience in industry, tweaked with academic experience and added in the salesman's skills of somebody else' (Interview 29/10/2013). But even if scientists strategically adopted the language of risk to respond to the EU, this had little impact on their practice. They accepted and welcomed 'risk' when they understood it as the uncertainty engrained in the process of research, rather than something to be avoided. This form of risk, too, was mitigated using professional and experiential knowledge, and while dancing with multiple forms of risks, they always maintained other options. 
Scientists were puzzled by our questions on the risks they encountered in their work. We had assumed that risk should be reduced, but they found it useful. They all stressed that risk is part of the scientific process and in ways not easily calculable in advance. One said: 'If you are developing any technology from a concept level the risk is always high even if you think that you have all the problems solved, it does not work like that. There are always problems that come up that you don't foresee especially if it's new' (Interview B, 8/11/2013).

To scientists, risk analysis was not probabilistic but qualitative, linked to a general sense of possibility of something failing or something not quite working the way it should. The notion of risk was a means of communicating this qualitative sense of uncertainty throughout the development of technology. This was evident in how they discussed ways to avoid risk. To some scientists, the most reasonable strategy was to consider an alternative: 'A de-risk strategy: it's building the software knowing it's going to have to all change. That's how I address it' (Interview B 24/10/2013). As the project developed, their idea of risk avoidance or analysis was mostly related to having a 'plan B': 'It's about your best effort to try and ensure that when things go wrong you have another strategy to try' (Interview A 29/10/2013). Again, the calculation of risk was not based on probabilistic calculus but on imagining possible alternatives. At times, this meant working on two possible methods simultaneously in case one failed. At other times, commercially available components were researched as a back-up plan. One 
scientist said: 'In the very beginning of the project when it was not clear at all whether this system will work or not, our particular module will work or not, we were looking for different systems by other manufacturers that have similar sizes, for example, similar power consumption, stuff like that, so that just for the worst case we would have a backup' (Interview A, 9/4/2014).

One of the most used strategies was to refer to the market. They looked at what was available on the market to explore alternatives or to select the option they thought was the most likely to be effective. For instance, the processing platform chosen initially had to be changed to accommodate the requirements of other new components as detection methods evolved (Interview A, 28/5/2014; Observation 3/3/2014). In discussions of the available literature, scientists referred to the market as the most valid source of knowledge: what others have done, what product is available or what exists, they said, limits some of the uncertainties.

Just as the guards at border sites made use of an implicit and unquantifiable sense of something beyond the normal, so too scientists worked on what they described as 'gut instinct' (Interview A, 28/5/2014). One said: 'we have some sort of gut feeling of what we need to understand, what we need to do...It's very difficult to convey this knowledge. So they do it based on experience and it's, it's like black magic' (Interview A, 28/5/2014). This 'gut feeling/black magic' suggests a mixture of personal technical knowledge, experience and imagination. One scientist described this relationship 
between knowledge and experience as the following: 'the only way I'm assessing or we're assessing risk is, one of experience. We've more experience with this technology so we know what the risks are, so we can assess them, okay? If you can't assess them properly then I put them in medium-high risk' (Interview D 8/11/13).

Risks were often resolved by scientists individually by making 'an educated guess' (Interview B, 24/10/2013). We understood this to mean the capacity to imagine the future either because they had tried it before or because it was common knowledge in their field. In other words, it was situated knowledge based on imaginations of what could possibly happen. This was not just about prior knowledge of facts and figures in specific scenario, however. It also included techniques and experiences of working through unexpected scenarios to make something work. Scientists stressed that risk and failure belong to the process itself, but they tended to see it as an essential component of creativity and the production of knowledge.

As Luhmann suggests (1993), risk is inherent to the scientific and commercial opportunities of technology development. In such cases, risk is looked upon with enthusiasm, especially at the initial stages of development. In the device we observed, variations in temperature or power or in the tilting/stability of the tool represented 'challenges' that could potentially be productive. One scientist said:

I guess the area of science that is the most challenging, and therefore offers potentially the biggest rewards, is biological detection, and that was not maybe 
as well defined as we thought it was at the start of the project, because the science revealed some interesting problems along the way. (Interview A 29/10/13)

Thus, in the first instance, risk was welcomed as inherent and potentially valuable. Then, when the risk of failure pushed back, they passed agency to the border guards, underlining previous discussion of the need to engage with the specific border contexts in which the device was to operate.

As noted above, the border guard end-users and their knowledge of everyday practices in different contexts was crucial. They suggested scenarios in which to imagine the technology at play, and their requirements limited the spaces of uncertainty. For this reason, their knowledge was often enrolled in the process of development: how is the device meant to work, in what context? What will guards do or what can they do, for how long, to what level of determination, etc.? Information was accepted without contestation as a way of acting on the uncertainties (and risks) of the process of experimentation. Scientists were happy to be constrained by these scenarios, as they helped them find solutions and gave them a greater sense that what they were doing was less likely to fail. When information was not directly provided, scientists extrapolated from end-users' stories of their experiences and their needs and the context in which they operated. 
Overall, scientists demonstrated that the totalizing logic of risk assumed at theoretical and policy level has not completely trumped more positive views of uncertainty and that in spite of the theoretical discourse on risk imperialism (Walklate and Mythen, 2011: 108) there are a number of different narratives and practices of risk management and assessment. Scientists talked of risk and uncertainty interchangeably. This was encountered in multiple ways - positive and negative. They negotiated risk and uncertainty through their personal specialized knowledge and the end-users' professional and experiential knowledge. They saw risk as an intricate part of the scientific development and they welcomed it for the potential rewards that overcoming it may bring. Risk became manageable in the production of a device intended to produce certainty at the border when different sets of experiential and professional knowledge joined together in the 'dance'.

Dancing with multiple risks: the return of experiential and professional knowledge

As, policing is becoming increasingly fragmented and pluralised, we looked at the roles of both the research groups and their partners (private and public) in the creation of a technological device to manage transnational policing issues through the detection of dangerous substances. Multiple actors determined the technology, with a strong role played by subjects positioned within the field of policing. This makes 
evident how situated experiential and contextual knowledge of specific fields contributed to shaping the device.

Further, power circulates and is activated by different subjects in the process of scientific development and in the determination of security at the border, following different rationalities and narratives of risks, of which those determined by states and supranational institutions are only part of the process and not necessarily the most significant ones. Rather, power is increasingly shared, with myriad actors setting up complex and hybrid arrangements of practices and mentalities. In the case of the handheld device, different risk logics were assembled together in the final security technology. The EU security concerns with catastrophic risk of CBRNE may have triggered the project and were never entirely forgotten, but the notions of risk actually driving the development of the device were quite different, incorporating the more mundane preoccupations of some policing agents, and the risks of technological development the scientists felt were more pressing. We do not see this as an example of 'mission creep', however, but as the epitome of a new modality whereby some actors enrolled in the provision of security through technology may not necessarily be visible to political scrutiny.

Our engagement with STS and the concepts of tuning and dancing allows us to register the ways in which different understandings of risk, danger, and security are assembled in one device. Even if a particular technology promises instantaneous 
certainty in the face of unknown risks at the border, in the case of the handheld device, the final determination on what to detect or how to devise the technology was not a simple technical arrangement in relation to the risk at the border, but rather the product of the assemblage of multiple forms and discourses of risk. Rather than operating through a bounded and actuarial knowledge of risk, the various actors involved danced with multiple risks, modes of risk assessment and risk management, among which the experiential and professional knowledge of situated past experiences and scenario creation were predominant. Even in the laboratories, there was no actuarial, probabilistic grounding for risk based decisions; only an assemblage of experiential, informal, affective and deeply social risk practices as scientists engaged with the material world of substances and matter. Likewise, if border guards, customs officials, and police act on the basis of information from the machine, they act on the basis not only of discovered fact but also on the contingent, lively, and unstable engagement of multiple forms of risk.

The official EU discourse of CBRNE risk was set against the working knowledge of risk at borders as selected by specific localised policing agents, and this combined with the scientific conception of risk and of development of technology in the lab. All these different discourses of risk were then combined in the security technology. Technological devices are the product of multiple forms of risk knowledge and management as they combine, sometimes conflict, and are translated into each other 
to connect the different worlds of policing agents, and the material contexts of borders and laboratories. In technological development, risk assessment involves a combination of technical and experiential knowledge since it emerges through the dance of devices, materials, and end users advice. So that what appears as a technical object is not simply the product of objective view of possibilities and probabilities but shot through with political assumptions, discretions, and uncertainties of the messy material world.

In this project, on the one hand, the device was intended to secure borders from CBRNE, on the other hand to aid investigative policing and trace criminal behaviour, and further, it was expected to detect illegal substances. Different forms of risk, their combinations and transformations, had an impact on the final device. For instance, in the move to merge the catastrophic and the mundane in the selection of target substances, the EU deferred to this redirection towards the mundane and accepted the relevance of practitioners' contextual experience and professional knowledge to determine risks at the border. We found that scientists similarly deferred to border professionals and policing agents, asking for their understanding of risks, as a way of making the technology more effective and heightening its possible competitive value and commercialization. The policing agents, in turn, espoused an understanding of security and risk related to their knowledge of everyday practices and challenges in specific contexts; their understanding was neither the actuarial calculation of risk nor solely the imagination of low probability, high consequence events, arguably 
evidencing the elision between expert knowledge and everyday experience. Scientists in the laboratories connected with this through their own combinations of experiential and scientific knowledge - using that to channel the challenges. Certainly they appealed to facts and figures to communicate this back to the end-users and funders, but this was often a translation and communication of experiential knowledge.

Thus, we continually observed the relevance of the everyday experience in the determination of risk in all spheres and at all levels of risk. We neither condemn nor celebrate this; rather, we call for its engagement as something inherent in the process of technologisation of risk and uncertainty.

\section{Funding}

This work was supported by the Economic and Social Research Council and the Defence Science and Technology Laboratory (grant number ES/K011332/1). The views expressed are those of the authors.

\section{References}


Aas KF (2005), 'Getting Ahead of the Game': Border Technologies and the Changing Space of Governance. In Zureik E and Salter MB (eds) Global Surveillance and Policing: Borders, Security, Identity, Abingdon: Willan Publishing, pp.194-214. Amoore L (2013) The Politics of Possibility: Risk and Security Beyond Probability. Duke University Press.

Aradau C and Van Munster R (2009) Exceptionalism and the 'War on Terror': Criminology Meets International Relations. British Journal of Criminology 49(5): 686-701.

Baillergeau ENMO and Duyvendak WJG (2016) Experiential Knowledge as a Resource to Coping with Uncertainty. Health, Risk \& Society 18(7-8): 407-426.

Beck U (1992) Risk Society: Towards a New Modernity. London: Sage.

Beck U (2013) World at Risk (trans. Ciaran Cronin). London: Polity.

Bigo D (2014) The (In)Securitization Practices of the Three Universes of EU Border Control: Military/Navy - Border Guards/Police - Database Analysts. Security Dialogue 45(3): 209-225.

Bigo D (2016) Rethinking Security at the Crossroad of International Relations and Criminology. British Journal of Criminology 56(6): 1068-1086.

Bourne M, Johnson H and Lisle D (2015) Laboratizing the Border: The Production, Translation and Anticipation of Security Technology. Security Dialogue 46(4): 307-325. 
Bowling B (2013) The Borders of Punishment: Towards a Criminology of Mobility. In: Bosworth M and Aas KF.(eds) The Borders of Punishment: Migration Control, Citizenship and Social Exclusion. Oxford: Oxford University Press. pp291-306. Bowling B, Marks A and Murphy C (2008) Crime Control Technologies: Towards an Analytical Framework and Research Agenda.In Brownsword R and Yeoung K (eds) Regulating Technologies: Legal Futures, Regulatory Frames, and Technological Fixes. London: Routledge. pp51-78.

Bowling B and Sheptycki JWE (2015) Global Policing and Transnational Law Enforcement. Vol 1, London: Sage.

Callon M, Lascoumes P and Barthe Y (Translated by Burchell, G) (2001) Acting in an Uncertain World: An Essay on Technical Democracy. Cambridge, MA: MIT Press.

Castel R (1991) From Dangerousness to Risk. In Burchell G, Gordon C and Miller P (eds) The Foucault Effect: Studies in Governmentality. University of Chicago Press. pp281-298.

Centre for Strategy and Evaluation Services (CSES), (2011) Ex-Post Evaluation of the Preparatory Action on Security Research: Interim Evaluation of FP7 Security Research: Final Report. Available at https://ec.europa.eu/homeaffairs/sites/homeaffairs/files/e- 
library/documents/policies/security/pdf/interim_evaluation_of_fp7_security_ex_ post_pasr_final_report_en.pdf (last accessed 24/03/17).

Ceyhan A (2008) Technologization of Security: Management of Uncertainty and Risk in the Age of Biometrics. Surveillance and Society 5(2): 102-123.

Clerke T and Hopwood N (2014) Doing Ethnography in Teams: A Case Study of Collaborative Research. Dordrecht: Springer.

Crawford A and Hutchinson S (2016) The Future(s) of Security Studies The British Journal of Criminology 56: 1049-1067

Deleuze G and Parnet C. (2007) Dialogues II, Columbia: Columbia University Press.

Douglas M (1994) Risk and Blame: Essays in Cultural Theory. London: Routledge.

Erickson K and Stull D (1998) Doing Team Ethnography: Warning and Advice. Thousand Oaks: Sage.

Ericson RV and Haggerty KD (1997) Policing the Risk Society. Oxford: Oxford University Press.

European Commission (2007) Green Paper on Detection Technologies for Law Enforcement, Customs and Other Security Authorities. Available at : https://ec.europa.eu/home-affairs/what-is-new/publicconsultation/2007/consulting_0011_en (last accessed 27/3/17).

European Commission (2010), Work Programme 2011: Cooperation: Theme 10: Security, Brussels, European Commission. Available at 
http://ec.europa.eu/research/participants/data/ref/fp7/89287/k-wp-201101_en.pdf Last accessed 20/11/17

European Commission (2014), Communication from the Commission to the European Parliament, The Council, The European Economic and Social Committee of the Regions on a new EU approach to the detection and mitigation of CBRN-E risks. COM (2014) 247 final. Available at: http://eur-lex.europa.eu/legalcontent/EN/TXT/PDF/?uri=CELEX:52014DC0247\&from=en

Falzon MA (ed) (2016) Multi- Sited Ethnography: Theory, Praxis and Locality in Contemporary Research. New York: Routledge.

Feeley M and Simon J (1992) The New Penology: Notes on the Emerging Strategy of Corrections and its Implications' Criminology 30( 4): 449-75.

Garland D (2001) The Culture of Control. Crime and Social Order in Contemporary Society. Chicago: University of Chicago Press.

Giddens A (1991) Modernity and Self Identity: Self and Society in the Late Modern Age. Cambridge University Press.

Guzik K (2016) Making Things Stick: Surveillance Technology and the Mexico’s War on Crime. University of California Press.

Haggerty K D and Ericson R (2000) The Surveillant Assemblage The British Journal of Sociology. 51(4): 605-622.

Hannah-Moffat K (1999) Moral Agent or Actuarial Subject: Risk and Canadian 
Women's Imprisonment. Theoretical Criminology 3(1): 71-94.

Hannah-Moffat K (2005) Criminogenic Needs and the Transformative Risk Subject:

Hybridizations of Risk/Need in Penality. Punishment and Society 7(1): 29-51.

Hannah-Moffat K, Maurutto P and Turnbull S (2010). Negotiated Risk: Actuarial Assessment and Discretion in Probation. Canadian Journal of Law and Society 24(3): 391-403.

Hutchinson S (2006) Countering Catastrophic Criminology Reform, Punishment and the Modern Liberal Compromise. Punishment \& Society 8(4): 443-67.

Kemshall H (2010) Risk Rationalities in Contemporary Social Work and Practice British Journal of Social Work 40: 1247-1262

Kemshall H and Maguire M (2001) Public Protection, Partnership and Risk Penalties: the Multi-agency risk management of Sexual and Violent Offenders Punishment and Society 3(2): 237-264.

Latour B (1987), Science in Action: How to Follow Scientists and Engineers Through Society. Cambridge MA, Harvard University Press.

Latour B and Woolgar (1979) Laboratory Life: The Social Construction of Scientific Facts. London: Sage.

Luhmann N (1993) Risk: A Sociological Theory. Berlin: de Gruyter Lyon D (ed) (2003) Surveillance as Social Sorting: Privacy, Risk and Digital Discrimination. London and New York: Routledge. 
Manning PK (2008) The Technology of Policing: Crime Mapping, Information Technology and the Rationality of Crime Control. New York: New York University Press

Marcus GE (1995) Ethnography in /of the World System: The Emergence of Multi Sited Ethnography Annual Review of Anthropology 24(1995): 95-117. Marx GT (2005) Some conceptual issues in the study of borders and surveillance'In Zureik E and Salter MB (eds) Global Surveillance and Policing: Borders, Security, Identity, Abingdon: Willan Publishing, pp.: 194-214.

Mythen G and Walklate S (2016) Counterterrorism and the reconstruction of (in)security: Divisions, Dualism, Duplicities. British Journal of Criminology 56(6): 1107-1124.

O Malley P (1992) Risk, Power and Crime Prevention Economy and Society 21:252-75. O’Malley P (1999):Volatile and Contradictory Punishment. Theoretical Criminology 3(2): 175-196.

O’Malley P (2004) Risk, Uncertainty and Government. London: Glass House.

Pickering A (1995) The Mangle of Practice: Time, Agency, and Science. Chicago: The University of Chicago Press.

Pickering A (2017) The Ontological Turn: Taking Different Worlds Seriously. Social Analysis 61(2): 134-150. 
Pickering S and Weber L (2006) Borders, Mobility and Technology of Control. In: Pickering S and Weber L (eds) Borders, Mobility and Technologies of Control. Dordrecht: Springer: pp.1-20.

Pickering S and Weber L (2013) Policing Transversal Borders. In: Bosworth M and Aas KF.(eds) The Borders of Punishment: Migration Control, Citizenship and Social Exclusion. Oxford: Oxford University Press pp.93-110

RNR Market Research (2016) CBRNE (Chemical, Biological, Radiological, Nuclear And Explosive) Detection Devices: Market Shares, Strategies, and Forecasts, Worldwide, 2016 to 2022 Available at http://www.rnrmarketresearch.com/cbrnechemical-biological-radiological-nuclear-and-explosive-detection-devicesmarket-shares-strategies-and-forecasts-worldwide-2016-to-2022-marketreport.html (last accessed 17/8/17).

Schuilenburg M (2015) The Securitization of Society: Crime, Risk and Social Order. New York University Press.

Valverde M (2011) Questions of Security: A Framework for Research. Theoretical Criminology 15(1): 3-22.

Visiongain (2016) Press Release: Global Police \& Law Enforcement Equipment Market To Be Worth \$7.08bn in 2016, available at: https://www.visiongain.com/Press_Release/1000/Global-Police-Law- 
Enforcement-Equipment-Market-To-Be-Worth-7-08bn-in-2016 (last accessed $5 / 6 / 17)$

Walklate S and Mythen G (2011) Beyond Risk Theory: Experiential Knowledge and Knowing Otherwise. Criminology and Criminal Justice 11(2): 99-113.

Werth R (2017) Individualizing Risk: Moral Judgement, Professional Knowledge, and Affect in Parole Evaluations. British Journal of Criminology 57(4): 808-827. Wilson D (2006) Biometrics, Borders and the Ideal Suspect In: Pickering S and Weber L (eds) Borders, Mobility and Technologies of Control. Dordrecht: Springer pp. 87-110.

Wonders N (2007) Globalization, Border Reconstruction Projects, and Transnational Crime. Social Justice 34(2): 33-46.

Wood J and Shearing C (2007) Imagining Security. Cullompton: Willan.

Zedner L (2009) Security. London: Routledge. 